\title{
Expression of a Gene for Glucan-binding Protein from Streptococcus mutans in Escherichia coli
}

\author{
By R. R. B. RUSSELL, ${ }^{*}$ D. COLEMAN ${ }^{2}$ AND G. DOUGAN ${ }^{2} \dagger$ \\ ${ }^{1}$ Dental Research Unit, Royal College of Surgeons of England, Downe, Orpington, Kent, UK \\ ${ }^{2}$ Department of Microbiology, Trinity College, Dublin 2, Ireland
}

(Received 17 August 1984; revised 27 September 1984)

The structural gene for a glucan-binding protein (GBP) of Streptococcus mutans has been inserted into a bacteriophage $\lambda$ vector and expressed in Escherichia coli $\mathrm{K} 12$. Lysates of $E$. coli infected with the recombinant phage contain an antigenic protein of the same size as $S$. mutans GBP. The GBP synthesized in $E$. coli can be affinity-purified on immobilized glucan and antiserum raised against it has been shown to precipitate fructosyltransferase activity from S. mutans.

\section{INTRODUCTION}

Streptococcus mutans is believed to be important in the initiation of dental caries (Hamada \& Slade, 1980) but investigation of certain aspects of its physiology and antigenic composition has been hampered by the lack of a system of genetic analysis. Recently, however, several authors have described the transfer of $S$. mutans genes to other organisms, using techniques of in vitro DNA manipulation (Holt et al., 1982; Jagusztyn-Krynicka et al., 1982; Macrina et al., 1980; Robeson et al., 1983). A genetic approach should be of particular value in studies of glucosyltransferase (GTF) and fructosyltransferase (FTF), extracellular enzymes of $S$. mutans which synthesize polymers from sucrose, since their products are involved in the formation and metabolism of dental plaque. Both GTF and FTF exist in multiple forms, the relationship of which is unclear (Russell, 1979a). In addition to GTF and FTF, S. mutans produces glucanbinding proteins which have been demonstrated to contribute to its ability to adhere to surfaces (Russell, 1979b; Douglas \& Russell, 1982; Russell et al., 1983a).

This paper describes the first use of bacteriophage $\lambda$ for the cloning of $S$. mutans genes and provides additional evidence for the recent observation (Russell et al., 1983a) that one of the $S$. mutans proteins which has the ability to bind to glucans is related to FTF. This glucan-binding protein has molecular weight of 74000 and is referred to here as GBP.

\section{METHODS}

Construction of gene bank. Details of the DNA manipulation techniques used have been described in detail elsewhere (Kehoe et al., 1983). Briefly, chromosomal DNA from $S$. mutans strain Ingbritt was partially digested with restriction endonuclease $S a u 3 A$ to give fragments in the 5-20 kbp range. These fragments were then cloned into the Bam HI sites of the replacement bacteriophage vector $\lambda$ L47.1 (Loenen \& Brammar, 1980) and packaged into phage particles in vitro. This phage population was then plated on an $E$. coli strain lysogenic for phage $\mathrm{P} 2$, in order to select recombinant phage (since only recombinants of $\lambda$ L47.1 in which the red and gam genes have been replaced by a cloned insert can grow on P2 lysogens). Plaques formed on the P2 lysogen were pooled to form a 'gene bank' stock.

† Present address; Bacteriology R \& D, Wellcome Research Laboratories, Beckenham, Kent, UK.

Abbreviations: FTF, fructosyltransferase; GTF, glucosyltransferase; GBP, glucan-binding protein. 
Screening of gene bank. The gene bank was plated on $E$. coli $\mathrm{C} 600$ to give approximately 500 plaques per plate. A disc of nitrocellulose with an embossed grid (Schleicher \& Schüll BA 85/23) was laid on top of the agar overlay and left in contact at $4{ }^{\circ} \mathrm{C}$ for at least $30 \mathrm{~min}$. The nitrocellulose disc was then placed in $0.05 \mathrm{M}-\mathrm{Tris} / \mathrm{HCl}(\mathrm{pH} \mathrm{7.5)}$ containing $0.15 \mathrm{M}-\mathrm{NaCl}$ (Tris/saline buffer, TSB) and $5 \%(\mathrm{w} / \mathrm{v})$ haemoglobin at $37^{\circ} \mathrm{C}$ for $1 \mathrm{~h}$. It was then shaken gently at room temperature for $2 \mathrm{~h}$ in TSB containing $5 \%(\mathrm{w} / \mathrm{v})$ haemoglobin and rabbit antiserum raised against $S$. mutans antigens, diluted $1 / 100(\mathrm{v} / \mathrm{v})$. The nitrocellulose disc was washed by shaking for $10 \mathrm{~min}$ in TSB, $10 \mathrm{~min}$ in TSB $+0.05 \%$ Nonidet P40 and 10 min in TSB (Burnette, 1981) before shaking for 90 min at room temperature in TSB $+5 \%(w / v)$ haemoglobin containing swine anti-rabbit serum conjugated to peroxidase, diluted 1/200 (Dako P217, Mercia Brocades, Weybridge, UK). The washing procedure was repeated as before and the nitrocellulose disc placed in $0.05 \mathrm{M}$-Tris $/ \mathrm{HCl}(\mathrm{pH} 7.5)$ containing $0.06 \%(\mathrm{w} / \mathrm{v})$ 4-chloro-1-naphthol (Sigma) and $0.01 \%(\mathrm{v} / \mathrm{v})$ $\mathrm{H}_{2} \mathrm{O}_{2}$ (Hawkes et al., 1982). In some experiments, instead of peroxidase-conjugated second antibody, rabbit antibody was located by means of sheep antiserum to rabbit immunoglobulins (Sigma) labelled with ${ }^{125}$ I by means of Iodobeads (Pierce \& Warriner Ltd, Chester, UK). Washing was as before, and the dried nitrocellulose disc was exposed to Kodak X-Omat AR film between two DuPont Lightning Plus intensifying screens at $-20^{\circ} \mathrm{C}$ (Swanstrom \& Shank, 1978). All phage plaques have a faint image due to binding of natural antibodies to E. coli present in the rabbit serum, but those in which $S$. mutans antigens were expressed were readily detectable by their greater intensity of labelling. Such positive plaques were purified by streaking and single plaques picked and stored over chloroform. Background labelling due to antibodies to $E$. coli was much less when the peroxidase conjugate was used, compared to radiolabelled conjugate.

Preparation of $E$. coli lysates. $\lambda$ vectors carrying $S$. mutans genes were diluted and plated on $E$. coli $\mathrm{C} 600$ so as to yield confluent lysis after $16 \mathrm{~h}$ incubation of plates at $37^{\circ} \mathrm{C}$. Then $2 \mathrm{ml}$ of $0.05 \mathrm{M}$-Tris/ $\mathrm{HCl}(\mathrm{pH} 7.5$ ) was added to each plate, and the soft agar layer was scraped off, macerated and placed in an ultrasonic bath for 15 min. The lysates were then centrifuged at $47000 \mathrm{~g}$ for $3 \mathrm{~h}$ to deposit agar and approximately $99 \%$ of the phage particles, leaving the proteins in the supernatant.

Electrophoresis. The conditions for SDS-PAGE and rocket- and crossed-immunoelectrophoresis were as described previously (Russell, 1979a,b). Proteins were transferred to nitrocellulose after SDS-PAGE (Western blotting) as described by Burnette (1981), antigens being detected as described above for gene bank screening.

Affinity chromatography. Glucan-binding proteins were purified by passing the $E$. coli lysates or $S$. mutans culture supernatant down a chromatography column made by mixing a slurry of $2 \mathrm{ml}$ Sepharose CL-6B (Pharmacia) with $200 \mathrm{mg}$ of the insoluble polymer mutan (synthesized by $S$. mutans GTF: Russell et al., 1983a). The column was eluted with $6 \mathrm{M}$-guanidine. $\mathrm{HCl}$ and fractions of $1 \mathrm{ml}$ were collected and dialysed against $0.05 \mathrm{M}$ Tris/ $\mathrm{HCl}$ buffer $(\mathrm{pH} \mathrm{7.5)}$ before analysis by SDS-PAGE, immunoelectrophoresis, or assay for FTF activity (Russell et al., 1983a).

\section{RESULTS}

The conditions chosen for cleaving the $S$. mutans chromosome with Sau3A should result in the entire gene bank being represented in approximately 1000 phage plaques. In our initial screening, approximately 1200 plaques were replica blotted to nitrocellulose and probed with a polyvalent antiserum to $S$. mutans, capable of detecting at least 12 antigens in crossed immunoelectrophoresis experiments. Seven plaques expressing $S$. mutans antigens were detected. These were purified by restreaking and lysates were prepared. Samples of the lysates were then examined for their antigen content by rocket immunoelectrophoresis using rabbit antisera specific for $S$. mutans wall-associated protein antigens A, B and C (Russell et al., 1983 b), GTF and GBP (Russell, 1979 $a$; Russell et al., 1983a). Four of the lysates gave precipitin peaks with the antiserum to GBP. The height of the rockets indicated that lysates contained $50 \mu \mathrm{g}$ GBP ml-1 a concentration approximately 100 times that found in cultures of $S$. mutans. None of the other lysates reacted with the sera tested, indicating that they contain antigens to which we do not yet have specific antisera or in amounts insufficient to be detected by rocket immunoelectrophoresis. However, by further screening of the gene bank with antisera directed against specific antigens, we have been able to find recombinant plaques in which other antigens, including antigens A, B and GTF, are expressed (R. R. B. Russell \& M. L. Gilpin, unpublished).

The antigen content of lysates of the GBP-recombinants was also examined by Western blotting. All four gave identical patterns, with a band of mol. wt 74000 identical in mobility to the GBP of $S$. mutans and an additional band, mol. wt 76500 , also reacting with antisera to GBP (Fig. 1). It has previously been reported that GBP from $S$. mutans tends to break down to yield 


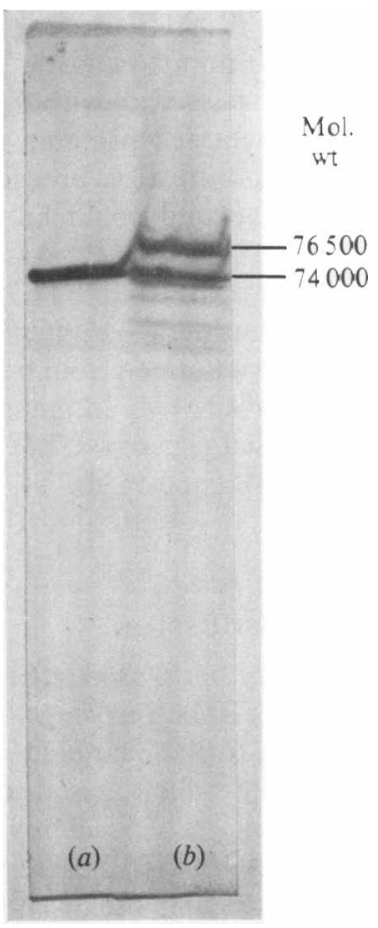

Fig. 1. Western blot of (a) $S$. mutans culture supernatant and (b) lysate of $E$. coli infected with recombinant $\lambda$ carrying the GBP gene. Antigens were located with antibody raised against pure $S$. mutans GBP.

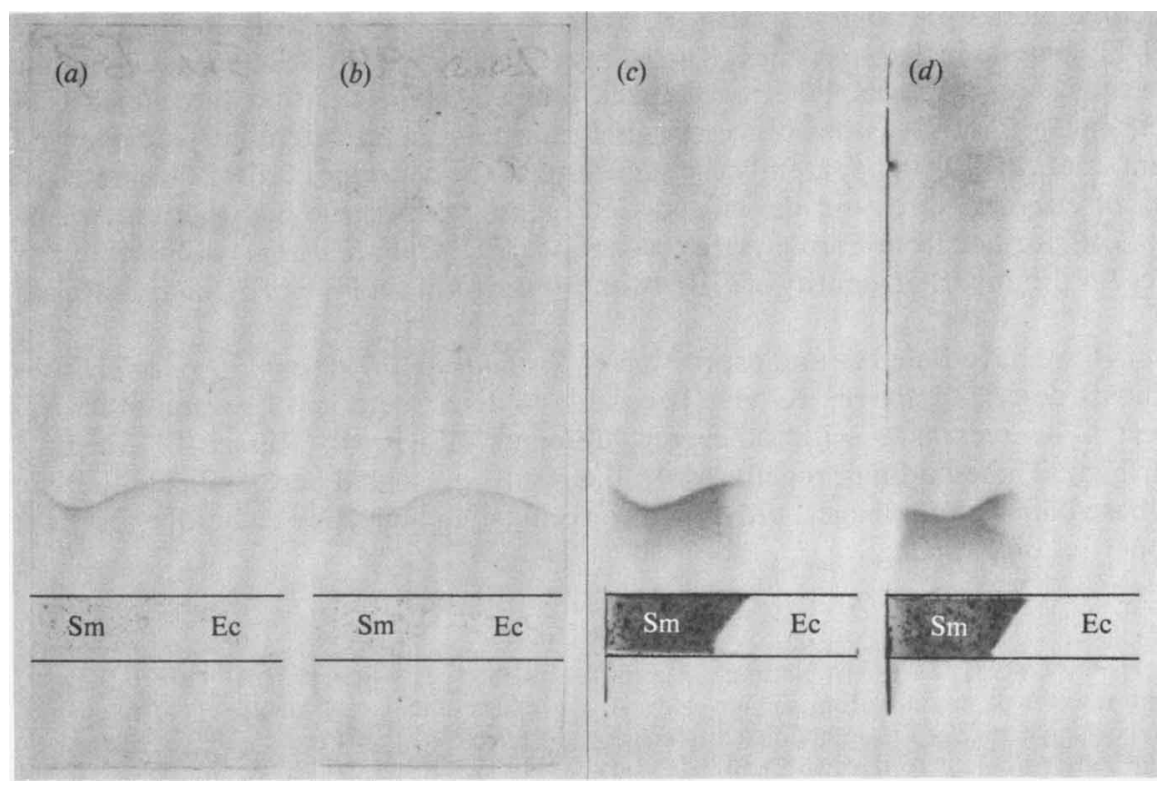

Fig. 2. Fused-line immunoelectrophoresis in which concentrated $S$. mutans culture supernatant (Sm) and lysate of $E$. coli $(\mathrm{Ec})$ infected with recombinant $\lambda$ specifying GBP were electrophoresed into antiserum raised against either GBP purified from $S$. mutans $(a, c)$ or against GBP produced in $E$. coli $(b$, $d)$. $(a)$ and $(b)$ show the immunoprecipitates stained with Coomassie Blue; $(c)$ and $(d)$ show the location of FTF activity detected by autoradiography of the same slides after incubation in $\left[{ }^{14} \mathrm{C}\right]$ sucrose. 
multiple bands in the mol. wt range 50000-70000 (Russell et al., 1983a) and the GBP in E. coli lysates (Fig. $1 b$ ) appears also to yield such minor bands.

Lysates of the GBP-recombinants were passed down affinity chromatography columns of immobilized mutan. After washing, the retained proteins were eluted and analysed by gel electrophoresis. This efficient, single-step purification procedure showed that both the 76500 and $74000 \mathrm{~mol}$. wt bands bound to mutan and could be eluted by soluble dextran or by chaotropic agents such as guanidine. $\mathrm{HCl}$.

To investigate the relationship between GBP and FTF further, antiserum was raised in rabbits by immunization with GBP produced in lysates of $E$. coli and purified by affinity chromatography. This antiserum precipitated antigen from both $S$. mutans and $E$. coli lysate, the single precipitation line showing identity of the two antigens (Fig. $2 b$ ). This identity was also revealed by reaction with antiserum raised against GBP from $S$. mutans (Fig. 2a). The precipitation lines formed by $S$. mutans GBP contained FTF activity whereas those formed by E. coli GBP did not (Figs $2 c, d$ ).

\section{DISCUSSION}

Cloning of $S$. mutans genes in E. coli has hitherto used either plasmid or cosmid vectors (Holt et al., 1982; Jagusztyn-Krynicka et al., 1982; Robeson et al., 1983). The use of $\lambda$ as a vector has a number of advantages, including the ability to clone large DNA fragments, the presence of the strong $\mathrm{pL}$ promoter and the fact that cloned products are released during lytic burst. The results presented above demonstrate that the expression of $S$. mutans antigens in recombinant plaques can readily be detected and, at least in the case of GBP, the responsible gene is transcribed by $E$. coli to yield a product that has the same molecular weight as, and is antigenically identical to, that made in $S$. mutans. The molecule of mol. wt 76500 most probably consists of GBP with an attached signal peptide which would normally be cleaved during export of GBP across the cytoplasmic membrane of $S$. mutans (Michaelis \& Beckwith, 1982).

The cloned GBP gene product, produced in $E$. coli, retains the ability of $S$. mutans GBP to bind to dextran or mutan. It does not, however, retain the FTF activity found in immunoprecipitates of $S$. mutans GBP. Although in early experiments we believed we could detect FTF activity in $E$. coli lysates (Russell et al., 1983a) we have not been able to reproduce those results. A possible explanation for lack of FTF activity is that the cloned GBP gene product, mol. wt 76500 , is not processed in $E$. coli to give an active enzyme even though a fragment, mol. wt 74000 , apparently the same size as the $S$. mutans GBP is generated. Despite the lack of enzyme activity in the cloned GBP gene product, the fact that antiserum raised against GBP purified from $E$. coli lysate precipitates FTF from $S$. mutans supports our previous evidence for the apparent identity of GBP to one of the forms of FTF of $S$. mutans (Russell et al., $1983 a$ ).

Although we have failed to find expression of $S$. mutans FTF activity in $E$. coli lysates in the experiments described above, we have been able to detect activity of several other $S$. mutans enzymes in lysates made with other recombinants (R. R. B. Russell \& M. L. Gilpin, unpublished). These findings, together with the results presented here, indicate that a cloning system based on bacteriophage $\lambda$ provides a convenient and effective technique for the study of the properties of $S$. mutans.

\section{REFERENCES}

BURNETTE, W. N. (1981). 'Western blotting': electrophoretic transfer of proteins from sodium dodecyl sulfate-polyacrylamide gels to unmodified nitrocellulose and radiographic detection with antibody and radioiodinated protein A. Analytical Biochemistry 112, 195-203.

Douglas, C. W. I. \& Russell, R. R. B. (1982). Effect of specific antisera on adherence properties of the oral bacterium Streptococcus mutans. Archives of Oral Biology 27, 1039-1045.
Hamada, S. \& Slade, H. D. (1980). Biology, immunology and cariogenicity of Streptococcus mutans. Microbiological Reviews 44, 331-384.

HaWkes, R., Niday, E. \& Gordon, J. (1982). A dotimmunobinding assay for monoclonal and other antibodies. Analytical Biochemistry 119, 142147.

Holt, R. G., Abiko, Y., Saito, S., Smorawinska, M., HaNSEN, J. B. \& CURTISs, R. (1982). Streptococcus mutans genes that code for extracellular proteins in 
Escherichia coli $\mathrm{K} 12$. Infection and Immunity 38, 147156.

JaGUSZTYN-KRYNiCKa, E. K., SMORAWINSKI, M. \& Curtiss, R. (1982). Expression of Streptococcus mutans aspartate-semialdehyde dehydrogenase gene cloned into plasmid pBR322. Journal of General Microbiology 128, 1135-1145.

Kehoe, M., Duncan, J., Foster, T., Fairweather, N. \& Dougan, G. (1983). Cloning, expression and mapping of the Staphylococcus aureus $\alpha$-hemolysin determinant in Esherichia coli K-12. Infection and Immunity 41, 1105-1111.

Loenen, W. A. M. \& Brammar, W. J. (1980). A bacteriophage lambda vector for cloning large DNA fragments made with several restriction enzymes. Gene 20, 249-259.

Macrina, F. L., Jones, K. R. \& Wood, P. H. (1980). Chimeric streptococcal plasmids and their use as molecular cloning vehicles in Streptococcus sanguis (Challis). Journal of Bacteriology 143, 1425-1435.

Michaelis, S. \& BeCKWITH, J. (1982). Mechanism of incorporation of cell envelope proteins in Escherichia coli. Annual Review of Microbiology 36, 435-465.
Robeson, J. P., Barletta, R. G. \& CURTiss, R. (1983). Expression of a Streptococcus mutans glucosyltransferase gene in Escherichia coli. Journal of Bacteriology 153, 211-221.

RUSSELL, R. R. B. (1979a). Glycosyltransferase of Streptococcus mutans strain Ingbritt. Microbios 23 , 135-146.

RusselL, R. R. B. (1979b). Glucan-binding proteins of Streptococcus mutans serotype $c$. Journal of General Microbiology 112, 197-201.

Russell, R. R. B., Jones, A. C. \& Douglas, C. W. I. $(1983 a)$. Fructosyltransferase activity of glucanbinding protein from Streptococcus mutans. Journal of General Microbiology 129, 3243-3250.

Russell, R. R. B., Peach, S. L., Colman, G. \& Colman, B. (1983b). Antibody responses to antigens of Streptococcus mutans in monkeys (Macaca fascicularis) immunized against dental caries. Journal of General Microbiology 129, 865-875.

Swanstom, R. \& Shank, P. R. (1978). X-ray intensifying screens greatly enhance the detection by autoradiography of the radioactive isotopes ${ }^{32} \mathbf{P}$ and ${ }^{125} \mathbf{I}$. Analytical Biochemistry 86, 184-192. 